\title{
Quantitative thallium-201 myocardial imaging in assessing right ventricular pressure in patients with congenital heart defects ${ }^{\star}$
}

\author{
MARLENE RABINOVITCH, KEITH C FISCHER, SALVADOR TREVES
}

From the Departments of Cardiology and Radiology, Children's Hospital Medical Center and the Departments of Pediatrics and Radiology, Harvard Medical School, Boston, Massachusetts, USA

SUMMARY Thallium-201 myocardial scintigraphy was performed in patients with congenital heart defects to determine whether, by quantification of right ventricular isotope uptake, one could assess the degree of right ventricular hypertrophy and so predict the level of right ventricular pressure. A total of 24 patients ranging in age from 7 months to 30 years was studied; 18 were studied before corrective surgery and six after operation. All but three had congenital heart defects which had resulted in pressure and/or volume-overload of the right ventricle. At routine cardiac catheterisation, $20 \mu \mathrm{Ci} / \mathrm{kg}$ thallium-201 as thallous chloride was injected through the venous catheter and myocardial images were recorded in anterior and left anterior oblique projections; these were subsequently analysed quantitatively and qualitatively.

Insignificant right ventricular thallium-201 counts judged as being less than 1 per cent of the injected dose or less than 0.3 of the left ventricular counts were present in six patients all with right ventricular peak systolic pressure $<30 \mathrm{mmHg}$. In the remaining 18 patients there was a good correlation between the right ventricular/left ventricular peak systolic pressure ratio and the right ventricular/left ventricular thallium-201 counts ratio. All patients with right ventricular/left ventricular peak systolic pressure less than 0.5 had right ventricular/left ventricular thallium-201 counts less than 0.4 . Qualitative evaluation of right ventricular isotope intensity proved helpful mainly in distinguishing the patients with right ventricular pressures at or above systemic levels. Thus quantitative analysis of myocardial imaging with thallium-201 is of use clinically in patients with congenital heart defects, in assessing the severity of pulmonary stenosis or the presence of pulmonary artery hypertension.

The right ventricular free wall is not normally visualised on thallium-201 myocardial scintigrams when the study is performed with the patient at rest, though it may be seen when the radio indicator is injected during exercise. ${ }^{1}$ Recent qualitative studies of myocardial imaging with thallium-201 in patients with pulmonary hypertension secondary to chronic airways disease ${ }^{2}$ and in patients with congenital heart defects causing pressure or volume overload of the right ventricle, ${ }^{34}$ have shown a prominent appearance of the right ventricular free wall caused by an apparent increase in thallium-201 uptake. It would be of particular value to be able to assess quantitatively by myocardial imaging of the right ventricle the severity of pulmonary or right ventricular hypertension, since other non-invasive

*Supported by NIH research grant and a training grant. Received for publication 11 June 1980 techniques such as electrocardiography, ${ }^{5}$ vectorcardiography, ${ }^{6}$ and echocardiography ${ }^{7}$ are limited in this respect, both technically and otherwise.

It has been shown both clinically ${ }^{1-12}$ and experimentally ${ }^{13}$ that the myocardial intensity of thallium-201 reflects myocardial perfusion and mass of the left ventricle. We have shown experimentally that myocardial uptake of thallium-201 also reflects right ventricular perfusion and mass. ${ }^{14}$ In our study in rats exposed to chronic hypobaric hypoxia, increased thallium-201 right ventricular counts were observed in proportion to the degree of right ventricular hypertrophy and of pulmonary artery hypertension which the animals had developed.

We have therefore studied in a group of patients, mostly children with congenital heart defects, the relation between the level of thallium-201 counts recorded in the right ventricle, and the degree of 
right ventricular or pulmonary artery hypertension, as measured at cardiac catheterisation.

\section{Subjects and methods}

\section{PATIENT POPULATION}

At the time of routine cardiac catheterisation, 24 patients underwent thallium-201 myocardial imaging. Informed consent was obtained for all studied in accordance with the provisions of our clinical investigation committee. The patients were aged between 7 months to 30 years (median age 5.5 years) (Table). Studies were made on 18 before surgical repair and on nine one to 12 years after operation. Of the preoperative patients, five had congenital heart defects with pressure overload of the right ventricle only, the diagnoses being valvular pulmonary stenosis in four and congenital mitral stenosis in one. Three patients had predominantly a volume-overload of the right ventricle, the diagnoses being coronary arteriovenous fistula in one and atrial septal defect in the other two. Seven patients had combined pressure and volume-overloads of the right ventricle, the diagnoses being common complete atrioventricular canal in two, double chamber right ventricle in two, secundum atrial septal defect and valvar pulmonary stenosis in one, secundum atrial septal defect and pulmonary branch stenosis in one, and d-transposition of the great arteries with pulmonary vascular obstructive disease in one. Three additional patients had left ventricular obstructive disease only, valvular aortic stenosis in

Table Patient population, haemodynamic and thallium-201 uptake data

\begin{tabular}{|c|c|c|c|c|c|c|c|c|c|c|}
\hline \multirow{2}{*}{$\begin{array}{l}\text { Case } \\
\text { no. }\end{array}$} & \multirow{2}{*}{ Age } & \multirow[t]{2}{*}{ Diagnosis } & \multicolumn{4}{|c|}{ Haemodynamic data } & \multicolumn{3}{|c|}{ Thallium-201 uptake data } & \multirow{2}{*}{$\begin{array}{l}\text { Right ventricle } \\
\text { overload type }\end{array}$} \\
\hline & & & $R V P S P$ & LVPSP & $Q p / Q s$ & $\begin{array}{l}\text { RVPSPI } \\
\text { LVPSP }\end{array}$ & $\begin{array}{l}R V^{\mathrm{u}} \\
\text { mean }\end{array}$ & $\begin{array}{l}L V^{u} \\
\text { mean }\end{array}$ & $\begin{array}{l}R V^{\mathbf{u}} / L V^{\mathbf{u}} \\
\text { mean }\end{array}$ & \\
\hline 1 & $7 \mathrm{mth}$ & $\begin{array}{l}\text { Valvar pulmonary } \\
\text { stenosis }\end{array}$ & 182 & 105 & $1 \cdot 0$ & $1 \cdot 7$ & $2 \cdot 2$ & 1.9 & $1 \cdot 2$ & Pressure \\
\hline $\begin{array}{l}2 \\
3\end{array}$ & $\begin{array}{l}7 \mathrm{mth} \\
8 \mathrm{mth}\end{array}$ & $\begin{array}{l}\text { Common AV canal } \\
\text { Secundum ASD } \\
\text { peripheral pulmonary } \\
\text { stenosis }\end{array}$ & $\begin{array}{l}50 \\
67\end{array}$ & $\begin{array}{r}69 \\
122\end{array}$ & $\begin{array}{l}4 \cdot 0 \\
2 \cdot 0\end{array}$ & $\begin{array}{l}0.7 \\
0.6\end{array}$ & $\begin{array}{l}1 \cdot 8 \\
1 \cdot 3\end{array}$ & $\begin{array}{l}2 \cdot 4 \\
2 \cdot 2\end{array}$ & $\begin{array}{l}0.8 \\
0.6\end{array}$ & $\begin{array}{l}\text { Pressure + volume } \\
\text { Pressure + volume }\end{array}$ \\
\hline $\begin{array}{l}4 \\
5\end{array}$ & $\begin{array}{l}11 \mathrm{mth} \\
22 \mathrm{mth}\end{array}$ & $\begin{array}{l}\text { Common AV canal } \\
\mathrm{S} / \mathrm{P} \text { total anomalous } \\
\text { pulmonary venous } \\
\text { connection correction }\end{array}$ & $\begin{array}{l}84 \\
28\end{array}$ & $\begin{array}{l}84 \\
89\end{array}$ & $\begin{array}{l}4 \cdot 5 \\
1 \cdot 0\end{array}$ & $\begin{array}{l}1 \cdot 0 \\
0 \cdot 3\end{array}$ & $\begin{array}{l}3 \cdot 0 \\
0.6\end{array}$ & $\begin{array}{l}3 \cdot 9 \\
2 \cdot 8\end{array}$ & $\begin{array}{l}0 \cdot 8 \\
0 \cdot 2\end{array}$ & $\begin{array}{l}\text { Pressure + volume } \\
\text { Postoperative }\end{array}$ \\
\hline 6 & $3 y$ & $\begin{array}{l}\text { Secundum ASD } \\
\text { pulmonary stenosis }\end{array}$ & 104 & 105 & $2 \cdot 0$ & $1 \cdot 0$ & $1 \cdot 2$ & $2 \cdot 1$ & 0.6 & Pressure \\
\hline 7 & $3 y$ & $\begin{array}{l}\mathbf{S} / \mathbf{P} \text { tetralogy of Fallot } \\
\text { correction }\end{array}$ & 68 & 90 & $1 \cdot 3$ & 0.8 & $1 \cdot 4$ & $1 \cdot 7$ & 0.8 & Postoperative \\
\hline $\begin{array}{l}8 \\
9\end{array}$ & $4 y$ & Primum ASD & 35 & 92 & $3 \cdot 0$ & 0.4 & $1 \cdot 0$ & $\begin{array}{l}2 \cdot 5 \\
2.5\end{array}$ & 0.4 & Volume \\
\hline $\begin{array}{r}9 \\
10\end{array}$ & $\begin{array}{l}4 y \\
4 y\end{array}$ & $\begin{array}{l}\text { Coronary AV fistula } \\
\text { Congenital mitral } \\
\text { stenosis }\end{array}$ & $\begin{array}{l}25 \\
38\end{array}$ & $\begin{array}{r}85 \\
100\end{array}$ & $\begin{array}{l}1 \cdot 5 \\
1 \cdot 0\end{array}$ & $\begin{array}{l}0.3 \\
0.4\end{array}$ & $\begin{array}{l}1 \cdot 0 \\
1 \cdot 1\end{array}$ & $\begin{array}{l}3 \cdot 5 \\
1 \cdot 8\end{array}$ & $\begin{array}{l}0.3 \\
0.6\end{array}$ & $\begin{array}{l}\text { Volume } \\
\text { Pressure }\end{array}$ \\
\hline 11 & $4 y$ & $\begin{array}{l}\text { Valvar pulmonary } \\
\text { stenosis }\end{array}$ & 126 & 108 & $1 \cdot 0$ & $1 \cdot 2$ & 1.5 & $1 \cdot 8$ & 0.8 & Pressure \\
\hline 12 & $5 y$ & $\begin{array}{l}\text { Aortic stenosis and } \\
\text { regurgitation }\end{array}$ & 16 & 105 & $1 \cdot 0$ & $0 \cdot 2$ & $2 \cdot 0$ & $3 \cdot 5$ & $<0.1$ & - \\
\hline 13 & $6 y$ & Secundum ASD & 28 & 90 & 2.6 & 0.3 & 0.4 & $3 \cdot 7$ & 0.1 & Volume \\
\hline 14 & $11 \mathrm{y}$ & Double chamber RV & $\begin{array}{l}66 \\
50\end{array}$ & 121 & $1 \cdot 4$ & 0.5 & $1 \cdot 7$ & $2 \cdot 4$ & $0 \cdot 8$ & Pressure + volume \\
\hline 15 & $12 y$ & $\begin{array}{l}\text { Correction } \\
\text { cotralogy of Fallot }\end{array}$ & 50 & 104 & $1 \cdot 0$ & 0.5 & $1 \cdot 3$ & $1 \cdot 7$ & 0.9 & Postoperative \\
\hline 16 & $14 \mathrm{y}$ & $\begin{array}{l}\text { S/P pulmonary stenosis } \\
\text { correction }\end{array}$ & 26 & 106 & $1 \cdot 0$ & 0.3 & 0.3 & $1 \cdot 6$ & 0.2 & Postoperative \\
\hline $\begin{array}{l}17 \\
18\end{array}$ & $\begin{array}{l}14 y \\
20 y\end{array}$ & $\begin{array}{l}\text { Aortic stenosis } \\
\text { Valvar pulmonary } \\
\text { stenosis }\end{array}$ & $\begin{array}{l}16 \\
73\end{array}$ & $\begin{array}{l}150 \\
108\end{array}$ & $\begin{array}{l}1 \cdot 0 \\
1 \cdot 0\end{array}$ & $\begin{array}{l}0 \cdot 1 \\
0 \cdot 7\end{array}$ & $\begin{array}{l}0.3 \\
0.6\end{array}$ & $\begin{array}{l}1 \cdot 8 \\
1 \cdot 4\end{array}$ & $\begin{array}{l}0.2 \\
0.5\end{array}$ & $\overline{\text { Pressure }}$ \\
\hline $\begin{array}{l}19 \\
20\end{array}$ & $\begin{array}{l}21 \mathrm{y} \\
21 \mathrm{y}\end{array}$ & $\begin{array}{l}\text { Double chamber RV } \\
\text { d-TGA pulmonary } \\
\text { vascular disease }\end{array}$ & $\begin{array}{r}43 \\
107\end{array}$ & $\begin{array}{l}110 \\
118\end{array}$ & $\begin{array}{l}1 \cdot 6 \\
1 \cdot 0\end{array}$ & $\begin{array}{l}0.4 \\
0.9\end{array}$ & $\begin{array}{l}0 \cdot 5 \\
2 \cdot 4\end{array}$ & $\begin{array}{l}1 \cdot 7 \\
2 \cdot 6\end{array}$ & $\begin{array}{l}0.4 \\
0.9\end{array}$ & $\begin{array}{l}\text { Pressure + volume } \\
\text { Pressure + volume }\end{array}$ \\
\hline $\begin{array}{l}23 \\
24\end{array}$ & $\begin{array}{l}27 \mathrm{y} \\
30 \mathrm{y}\end{array}$ & $\begin{array}{l}\text { Aortic stenosis } \\
\mathbf{S} / \mathbf{P} \text { tetralogy of Fallot } \\
\text { correction }\end{array}$ & $\begin{array}{l}21 \\
65\end{array}$ & $\begin{array}{l}120 \\
100\end{array}$ & $\begin{array}{l}1 \cdot 0 \\
1 \cdot 0\end{array}$ & $\begin{array}{l}0 \cdot 2 \\
0 \cdot 7\end{array}$ & $\begin{array}{l}0 \cdot 2 \\
1 \cdot 4\end{array}$ & $\begin{array}{l}2 \cdot 5 \\
2 \cdot 2\end{array}$ & $\begin{array}{r}<0.1 \\
0.6\end{array}$ & Postoperative \\
\hline
\end{tabular}

Abbreviations : RVPSP, right ventricular peak systolic pressure; LVPSP, left ventricular peak systolic pressure; Qp/Qs, pulmonary systemic flow ratio; $R V^{u}$, right ventricular thallium-201 uptake; $L V^{u}$, left ventricular thallium-201 uptake; $R V^{u}$ mean, $L V u$ mean, mean of values between observer I and II; ASD, atrial septal defect; AV canal, atrioventricular canal; S/P, status post; d-TGA, d-transposition of great arteries; coronary AV fistula, coronary arteriovenous fistula; -, not applicable. 
two, and valvular aortic stenosis with regurgitation in one.

Of the six postoperative patients, three had no evidence of residual pressure or volume-overload of the right ventricle: one had had repair of a primum atrial septal defect, the other had had correction of total anomalous pulmonary venous connection, and the third had had a pulmonary valvulotomy. Three patients had significant residual pressure-overload of the right ventricle; all had had tetralogy of Fallot repaired.

\section{HAEMODYNAMIC STUDY}

Haemodynamic data obtained at cardiac catheterisation, which were correlated with the scintigraphic data, included measurements of right and left ventricular and pulmonary artery pressures, both systolic and end-diastolic. Pulmonary and systemic blood flows and resistances were calculated by the Fick principle on the basis of the measured oxygen consumption. Normal values were taken from previously published data. ${ }^{15}$

\section{SCINTIGRAPHIC STUDY}

At the end of the cardiac catheterisation, after the haemodynamic data had been obtained and the cineangiograms taken, $20 \mu \mathrm{Ci} / \mathrm{kg}$ thallium-201 as thallous chloride (minimum $500 \mu \mathrm{Ci}$, maximum $1.5 \mathrm{mCi}$ ) was injected through the venous catheter, positioned at the inferior vena cava right atrial junction. The catheters, arterial and venous, were then withdrawn and haemostasis achieved. Since it is conceivable that contrast angiography may have increased the uptake of thallium-201 through reactive myocardial hyperaemia, in one-third of the patients, selected at random, we injected the isotope 24 hours later via the brachial vein. We were therefore able to assess whether the technique of injection or time after contrast angiography had any effect on our results.

Thirty minutes after injection of the isotope, imaging was begun on a gamma camera equipped with a high resolution, parallel hole collimator (Searle LEM). The camera was interfaced to a computer (Digital Equipment Corporation) and $64 \times 64$ images obtained in the anterior, 45 and 60 degree left anterior oblique projections. Three hundred thousand count images were obtained in four to 12 minutes in each view. In addition, a count rate was recorded on the computer for the original syringe containing the thallium-201 dose and for the syringe after injection, using the same background. No attempt was made to correct for absorption.

The image showing the best separation of the left ventricle from the right ventricle was selected. In all cases this proved to be one of the left anterior

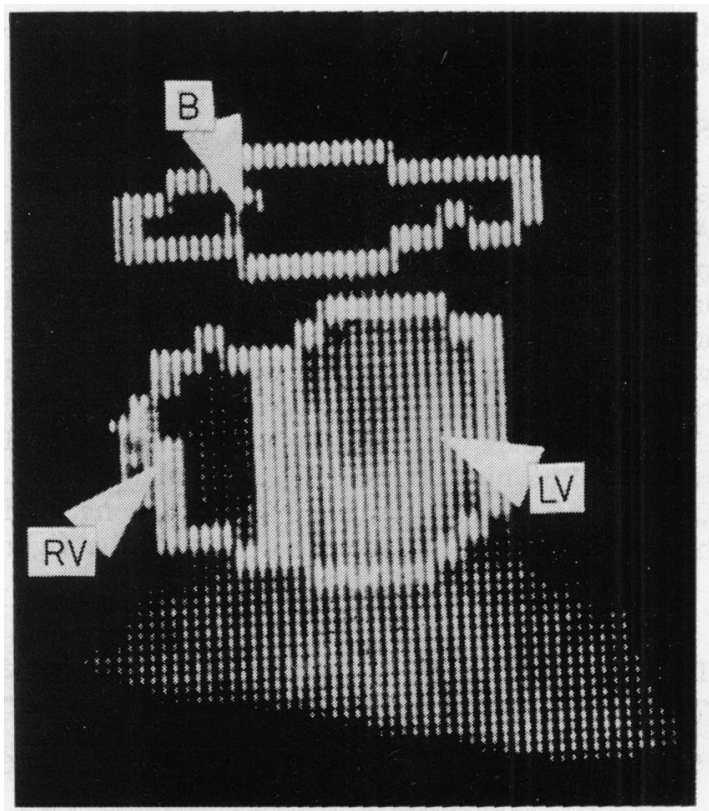

Fig. 1 A thallium-201 myocardial scintigram is seen in left anterior oblique projection. Regions of interest have been taken over the right ventricle $(R V)$ and over the left ventricle and septum ( $L V)$ to compute the percentage right and left ventricular thallium-201 counts. $B$, background.

oblique views. Regions of interest were marked over the right ventricle as well as over the left ventricle plus septum, and a background area was selected over the lung and mediastinum (Fig. 1). A computer program was developed to calculate the following: (i) percentage right ventricular counts of the injected dose; (ii) percentage left ventricular counts of the injected dose; (iii) the ratio of right ventricular counts to background; (iv) the ratio of left ventricular counts to background, and (v) the ratio of right ventricular to left ventricular counts. All measurements were corrected for background.

This image was analysed visually as well as quantitatively. For visual analysis all images were adjusted so that the maximum intensity level was set over the left myocardium and 20 per cent background was subtracted. The display had 16 digital intensity levels. Visualisation of the right ventricle was graded by a modification of the method suggested by Cohen et al. ${ }^{2}: 0$, no visualisation of the right ventricle; $0^{+}$very minimal visualisation of the right ventricle; 1 , definite visualisation of the right ventricle, with counts recorded less than for the left ventricle; 2 , counts of the right ventricle equal to the left ventricle; and 3, counts of the right ventricle greater than those of the left ventricle (Fig. 2). 


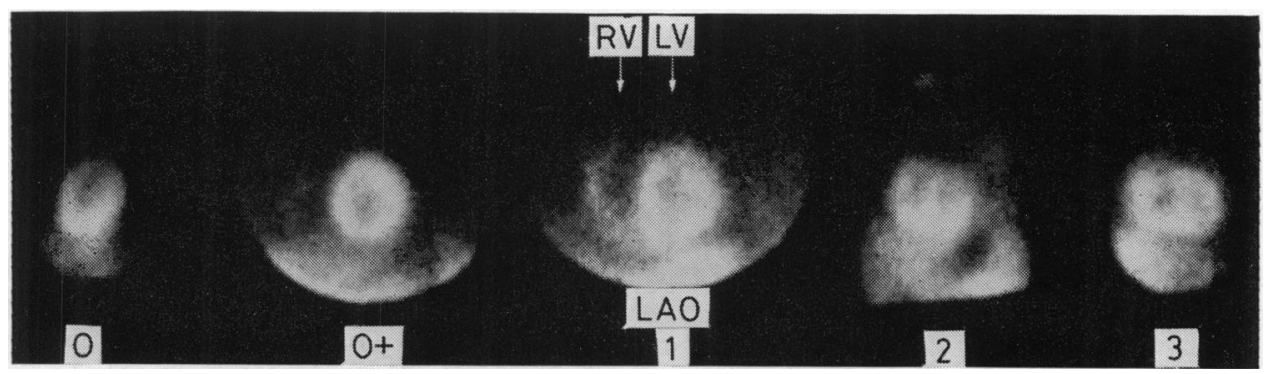

Fig. 2 All thallium-201 scintigraphic myocardial images are viewed in left anterior oblique projection (LAO) : 0 shows a well-defined left ventricular wall with no right ventricular wall image; $0^{+}$shows a faint shadow of the right ventricular free wall; 1 shows a definite image of the right ventricular wall but less dense than that of the left ventricle; 2 shows equally dense right and left ventricular images; and 3 shows $x$ thicker and denser appearance of the right ventricular free wall, compared with that of the left ventricle. $R V$, right ventricle; LV, left ventricle.

\section{ANALYSIS OF DATA}

Two different observers analysed the scintigraphic data, both without knowledge of the haemodynamic data. Right ventricular counts recorded were judged to be insignificant if they were less than 1 per cent of the injected dose, or if measured at less than 0.3 of the uptake of the left ventricle. For all those cases with significant right ventricular uptake, that is with levels above the values indicated, correlations were established, by linear regression plots, between the level of right ventricular thallium201 counts and the level of right ventricular peak systolic pressure and between the ratio of right to left ventricular $(\mathrm{RV} / \mathrm{LV})$ thallium-201 counts and the ratio of RV/LV peak systolic pressure. Correlations were also established between right ventricular thallium-201 counts and RV/LV peak systolic pressure between $\mathrm{RV} / \mathrm{LV}$ thallium-201 counts and right ventricular peak systolic pressure.

Postoperative patients were evaluated both separately and as part of the group. Comparisons were made between patients with separate and combined volume and pressure-overloads of the right ventricle. When the qualitative method of analysis was used, significant differences in the thallium-201 counts groups as graded 0 to 3 and between their mean right ventricular peak systolic pressure or their mean RV/LV peak systolic pressure ratio were established by Student's $t$ test.

Because of differences between the two observers in choosing the regions of interest over the right ventricle and over the left ventricle and septum, there was some variation in the values given for right ventricular as well as for left ventricular thallium-201 counts. Since there was consistency, however, in that each observer reported values for right ventricular or left ventricular counts as being either both larger or both smaller than did the other, there was good agreement when the values were expressed as the "counts ratio". Both observers graded the images qualitatively in an identical manner.

Electrocardiograms were available on all patients and echocardiograms on about one in four and these were also compared with the scintigraphic data. Electrocardiographic voltage criteria and systolic time intervals for assessing the degree of pulmonary artery hypertension were taken from previously published data. ${ }^{16} 17$

\section{Results}

QUANTITATIVE EVALUATION OF RIGHT VENTRICULAR THALLIUM-201 UPTAKE (Fig. 3)

Insignificant right ventricular thallium-201 counts were recorded in six patients all with right ventricular peak systolic pressures of less than 30 $\mathrm{mmHg}$. These were all three patients with aortic stenosis, one patient with a volume overload of the right ventricle (case 13), and two patients evaluated at least one year after corrective surgery, in whom right ventricular pressures had become normal (cases 5 and 16).

The remaining 18 patients all had significant right ventricular counts recorded, and right ventricular peak systolic pressures ranged from 25 to $182 \mathrm{mmHg}$. There were two patients with a volume overload of the right ventricle (cases 8 and 9), all patients with pure pressure-overloads of the right ventricle, and those with combined pressure and volume overloads.

The RV/LV thallium-201 counts ratio correlated well with $\mathrm{RV} / \mathrm{LV}$ peak systolic pressure ratio, as judged by a correlation coefficient $r$ of 0.81 ; the RV/LV thallium-201 counts ratio also correlated well with the level of right ventricular peak systolic pressure, $r$ of $0.78(p<0.001$ for both, Fig. 3 


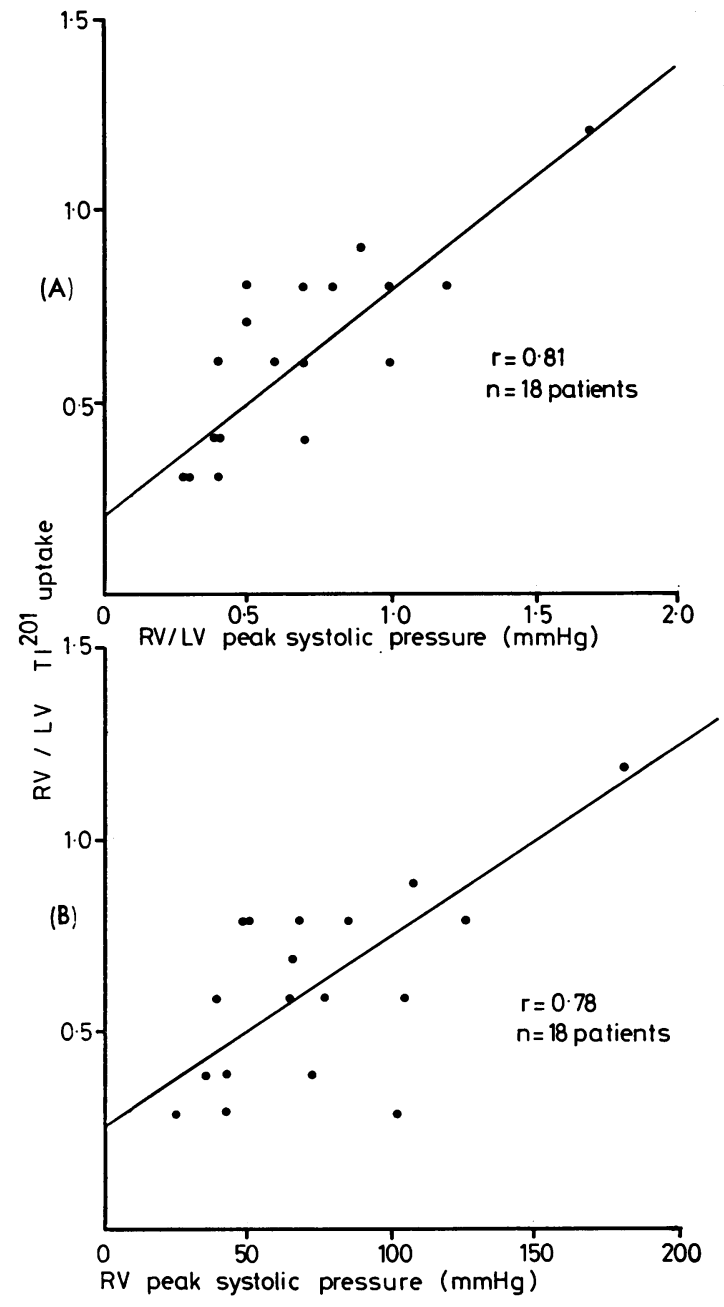

Fig. 3 ( $A$ ) The correlation between the measurement of right to left ventricular thallium-201 counts ratio (RV/LV TI ${ }^{201}$ ) (in the 18 patients in whom this ratio was significant) and the measurement of the ratio of right to left ventricular ( $R V \mid L V)$ peak systolic pressure. The correlation coefficient is $r=0.81$; the formula is $R V\left|L V T I^{201}=0.55 R V\right| L V$ peak systolic pressure $+0.25 \pm 0.14(p<0.001)$. (B) The correlation between the measurement of right to left ventricular thallium-201 counts ratio and the measurement of right ventricular peak systolic pressure. The correlation coefficient is $r=0.78$; the formula is $R V \mid L V T I^{201}=$ $0.005 R V$ peak systolic pressure $+0 \cdot 29 \pm 0 \cdot 15$ $(p<0.001)$.

A and B). All patients with right ventricular peak systolic pressures at half systemic levels or greater had RV/LV thallium-201 counts ratios at/or greater than 0.4 .

The per cent right ventricular thallium-201 counts correlated less well than did the RV/LV ratio with either the level of right ventricular peak systolic pressure $(r=0.56)$ or with the $R V / L V$ peak systolic pressure ratio $(r=0 \cdot 63)$.

\section{QUALITATIVE EVALUATION OF RIGHT VENTRICULAR COUNTS (Fig. 4)}

In two patients (cases 17 and 23) the right ventricle could not be visualised at all (grade 0 ): both had aortic stenosis (right ventricular peak systolic pressure 16 to $21 \mathrm{mmHg}$ ). In six patients, there was

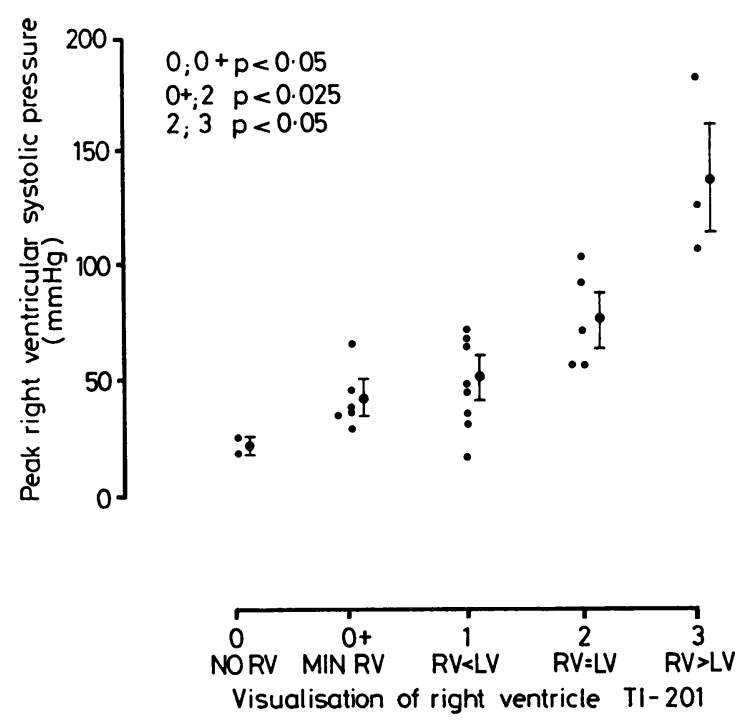

Fig. 4 Qualitative assessment of right ventricular hypertrophy by thallium-201 counts according to the grading system. No $R V$ indicates no detectable $R V$ counts, min $R V$ indicates minimal $R V$ counts;

$R V<L V$ indicates $R V$ counts definite but less dense than of the $L V ; R V=L V$ is equal density of $R V$ than $L V$ counts. $R V>L V$ is greater density of $R V$ than $L V$ counts. Mean and $S E$ are given for each group; $p$ values are recorded in the upper left hand corner.

minimal visualisation of the right ventricle (grade $0^{+}$); there were two patients with right ventricular volume overload (cases 9 and 13), two patients with mild to moderate right ventricular pressure overload (cases 3 and 19), and two patients with normal postoperative haemodynamics (cases 5 and 21). The right ventricular peak systolic pressure for the latter group ranged from 25 to 67 $\mathrm{mmHg}$ (mean $=36.7 \pm 6.6 \mathrm{mmHg}$ SEE).

Eight patients showed definite visualisation of the right ventricle, with counts recorded less than over the left ventricle (grade 1). Included were the remaining patient with aortic stenosis (case 12), 
another patient with right ventricular volumeoverload (case 8 ), three patients with right ventricular pressure-overload (cases 10, 18, and 22), one with normal postoperative haemodynamics (case 16) and two patients with combined right ventricular pressure- and volume-overload (cases 14 and 24). The right ventricular peak systolic pressure for the group ranged from 16 to $73 \mathrm{mmHg}$ (mean = $46 \pm 7.0 \mathrm{mmHg} \mathrm{SE})$.

Five patients had right ventricular thallium-201 counts equal in intensity to those of the left ventricle (grade 2). Included were three patients with combined right ventricular pressure and volume overload (cases 2, 4, and 6) and two patients with residual postoperative right ventricular hypertension (cases 7 and 15). The right ventricular peak systolic pressures for this group ranged from 50 to 104 $\mathrm{mmHg}$ (mean $=71.2 \pm 10.3 \mathrm{mmHg} \mathrm{SE}$ ).

Three patients (cases 1,11 , and 20 ) showed right ventricular counts greater than for the left ventricle (grade 3). All three had severe right ventricular pressure overload, and one, in addition, had right ventricular volume overload. Their right ventricular peak systolic pressures ranged from 107 to 182 mmHg (mean $=138 \pm 22.5 \mathrm{mmHg} \mathrm{SE}$ ).

It was possible by the grading method to distinguish the two groups with the very highest right ventricular pressures from the three other groups who had normal pressures or lower degrees of increase $(p<0.005)$. Group 0 could be distinguished from $0^{+}$with a value $\mathrm{p}<0.05$, group $0^{+}$or group 1 from group 2 ( $p<0.025)$, and group 2 from group $3(p<0.05)$. It was impossible, however, to distinguish some patients with right ventricular pressures in the normal range from those in whom values were as high as three-quarters of systemic levels.

\section{GENERAL COMMENTS}

There was no difference in the correlation of scintigraphic and haemodynamic data between those patients studied at the time of cardiac catheterisation and those studied the following day. Pressure overload alone seemed the most important determinant of right ventricular thallium-201 uptake, that is the highest counts were in the patients with the highest right ventricular pressures. The addition of a volume overload did not influence the data. Among the patients studied one year after operation, right ventricular thallium-201 counts reflected the presence of any residual defect causing raised right ventricular pressure.

\section{OTHER NON-INVASIVE STUDIES}

Right ventricular hypertrophy was detected on all electrocardiograms of patients with right ventricular hypertension before operation. In five patients studied postoperatively, however, the development of right bundle-branch block in three was not helpful as an indicator of residual pulmonary stenosis, and the persistence of right ventricular hypertrophy in two others did not reflect complete regression of their preoperative right ventricular hypertension.

M-mode echocardiograms were available from only six patients in this series. In three, the studies were limited and did not include evaluation of right ventricular systolic time intervals; in the other three, it was not possible to obtain right ventricular systolic time intervals because of the presence of complete right bundle-branch block. ${ }^{7}$ Hence, no echocardiographic data are available for comparison with the radionuclide data for estimation of the level of pulmonary artery pressure.

\section{Discussion}

\section{PREVIOUS METHODS}

In previous studies of myocardial imaging with thallium-201 the degree of right ventricular hypertrophy has been qualitatively evaluated according to a grading system suggested by Cohen et al. ${ }^{2}$ It had been observed by these workers, in patients with pulmonary disease, that when pulmonary artery hypertension was present, scintigraphic studies with thallium-201 produced an image of the right ventricle equal to or greater in intensity than that of the left ventricle. Among the patients studied, however, there was not a good correlation between the level of pulmonary artery pressure and the intensity of isotope visualised. In other studies of myocardial imaging with thallium-201 by Khaja et al. ${ }^{4}$ and Kondo et al. ${ }^{3}$ the observation was made that volume overload of the right ventricle alone could be associated with abnormally increased right ventricular isotope visualised, but the image of the right ventricle was usually less dense in appearance than that of the left ventricle.

Our results differ somewhat from those of the previous investigators. Unlike Cohen et al., ${ }^{2}$ we did find significantly higher levels of right ventricular or pulmonary artery pressure in the group of patients in whom the image of the right ventricle was more dense than that of the left ventricle compared with the group in which the images were equally dense. This could be because we were studying a younger patient population and one with congenital heart defects which had caused an increase in pulmonary artery or right ventricular pressure from early infancy. The patients in the series of Cohen et al. ${ }^{2}$ were older and they had acquired pulmonary parenchymal disease which had resulted in the later development of pulmonary 
artery hypertension. Hence, there may have been more variation in their degree of right ventricular hypertrophy response.

In our study, the patients with volume overload of the right ventricle tended to be similar to those with normal right ventricular pressure and volume in the degree of right ventricular thallium-201 counts recorded and did not form as easily distinguishable a group as they did in the series of Kondo et al. ${ }^{3}$ and Khaja et al. ${ }^{4}$ There are two possible explanations for this difference; first, we studied very few patients in the category of predominant right ventricular volume overload, and secondly the right ventricles of patients we did study were less severely affected. This is judged by the fact that our patients had normal values of right ventriculur end-diastolic pressure ${ }^{15}$ whereas in the previous study the patients tended to have significantly increased values.

\section{QUANTITATIVE APPROACH}

Cohen et al. ${ }^{2}$ considered right ventricular hypertrophy to be present if the thickness of the right ventricular free wall was greater than $1 \mathrm{~cm}$. These authors, however, did not find a good correlation between the level of right ventricular hypertension and the degree of increased right ventricular wall thickness. As ages and body surface areas varied widely in our patients, we thought that establishing a single dimension of right ventricular wall thickness as a standard of comparison was probably not reliable. For this reason we chose to quantify total percentage right ventricular counts. Since, however, previous studies have documented that exercise increases the percentage myocardial counts recorded of thallium-201 ${ }^{1}$ and since most of the patients in our series were studied after cardiac catheterisation and therefore in different states of sedation, we expected that the increase in right-toleft ventricular ratio of thallium-201 counts would be a more reliable indicator of the presence and severity of right ventricular hypertension than would the absolute value of right ventricular uptake. Indeed, we found that by using the counts ratio we could most effectively distinguish the group of patients with raised right ventricular pressure from the one in which right ventricular pressure was normal. Of perhaps even greater importance is the finding that we could also identify the patients with pulmonary artery pressure of greater than half systemic levels, from those with milder degrees of pressure rise. In this way, the quantitative assessment proved superior to the qualitative, where it was possible to distinguish reliably only the patients with right ventricular pressures at or above systemic levels. The overlap seen even among the patients studied quantitatively represents the likelihood that thallium-201 myocardial uptake is a function of several determinants, pressure being one, but myocardial mass and coronary blood flow being others. ${ }^{13}$ There is probably some individual variation which influences how the three determinants interrelate.

It is of interest that when a combined pressure and volume-overload is present, the pressure overload seems to be the most important determinant of the relative level of thallium-201 right ventricular uptake. Thus, the thallium-201 scintigram can serve as a useful screening test in evaluating the severity of valvar or infundibular pulmonary stenosis. Moreover, it can also serve to identify, among the right ventricular volume overload patients, those who also have pulmonary artery hypertension. The use of serial studies to evaluate progression of pulmonary stenosis or progression or regression of pulmonary artery hypertension merits further investigation.

Finally, in the limited number of patients studied postoperatively, the increase in right ventricular thallium-201 uptake reflects the presence of residual defects causing persistent increases in right ventricular pressure. The ultimate usefulness of the postoperative study will have to be further tested in a larger number of patients of different ages with varying preoperative and postoperative right ventricular pressure and volume overloads, and at different times postoperatively. It is likely that reliable postoperative evaluation of residual right ventricular hypertension will be a function of the age of the child at repair, the severity of preoperative right ventricular pressure rise, and the length of time interval since repair.

It has been shown by Rimoldi et al. ${ }^{18}$ in a necropsy study that the right to left ventricular mass ratio is constant after the first three months of life. Thus, myocardial imaging, to detect right ventricular hypertrophy, is probably applicable only to those patients older than 3 months of age, where it would anyway be clinically most helpful.

\section{COMPARISON WITH OTHER}

NON-INVASIVE STUDIES

In patients with right bundle-branch block, the postoperative electrocardiogram, echocardiogram, and vectorcardiogram are ineffective in assessing the severity of residual right ventricular hypertension. In addition, in many patients, the pulmonary valve does not show up well enough on the echocardiogram for accurate determination of right ventricular systolic time intervals. Obtaining a satisfactory echocardiogram is especially difficult in patients with pulmonary disease such as cystic 
fibrosis, because of the hyperinflated state of the lungs. ${ }^{17}$ Thus, where the other non-invasive studies are limited, the evaluation of right ventricular and pulmonary artery hypertension by quantitative myocardial scintigraphy is particularly helpful not only diagnostically but also in following the influence of different modes of treatment.

\section{Conclusion}

Quantitative myocardial imaging of right ventricular hypertrophy with thallium-201 in patients with congenital heart defects is a useful screening test for the detection of right ventricular hypertension. Total right ventricular counts of less than 1 per cent of injected dose or right to left ventricular counts ratios of less than or equal to 0.3 are associated with right ventricular peak systolic pressures at less than half systemic levels. This proves true whether the increased right ventricular pressure reflects pulmonary stenosis or pulmonary artery hypertension and does not appear to be influenced by the presence of an additional right ventricular volume overload.

We thank Dr Alexander S Nadas for his interest in this work and for reviewing this manuscript. We also thank New England Nuclear Radiopharmaceuticals for supplying thallium-201.

\section{References}

1 Hamilton GW, Trobaugh GB, Ritchie JL, Williams DL, Weaver WD, Gould KL. Myocardial imaging with intravenously injected thallium-201 in patients with suspected coronary artery disease: analysis of technique and correlation with electrocardiographic, coronary anatomic, and ventriculographic findings. Am $\mathcal{F}$ Cardiol 1977; 39: 347-54.

2 Cohen HA, Baird MG, Rouleau JR, et al. Thallium201 myocardial imaging in patients with pulmonary hypertension. Circulation 1976; 54: 790-5.

3 Kondo M, Kubo A, Yamazaki H, et al. Thallium-201 myocardial imaging for evaluation of right-ventricular overloading. F Nucl Med 1978; 19: 1197-203.

4 Khaja F, Alam M, Goldstein S, Anbe DT, Marks DS. Diagnostic value of visualization of the right ventricle using thallium-201 myocardial imaging. Circulation 1979; 59: 182-8.

5 Johnson JB, Ferrer MI, West JR, Cournand A. The relation between electrocardiographic evidence of right ventricular hypertrophy and pulmonary arterial pressure in patients with chronic pu'monary disease. Circulation 1950; 1: 536-50.

6 Chou TC, Masangkay MP, Young R, Conway GF, Helm RA. Simple quantitative vectorcardiographic criteria for the diagnosis of right ventricular hypertrophy. Circulation 1973; 48: 1262-7.

7 Williams RG, Tucker CR. Echocardiographic diagnosis of congenital heart disease. Boston: Little, Brown, 1977: 163-70.

8 Strauss HW, Harrison K, Langan JK, Langan RT, Lebowitz E, Pitt B. Thallium-201 for myocardial imaging. Relation of thallium-201 to regional myocardial perfusion. Circulation 1975; 51: 641-5.

9 Pitt B, Strauss HW. Myocardial imaging in the noninvasive evaluation of patients with suspected ischemic heart disease. Am $\mathcal{f}$ Cardiol 1976; 37: 797-806.

10 Bulkley BH, Rouleau J, Strauss HW, Pitt B. Idiopathic hypertrophic subaortic stenosis: detection by thallium-201 myocardial perfusion imaging. $N$ Engl f Med 1975; 293: 1113-6.

11 Bailey IK, Come PC, Kelly DT, et al. Thallium-201 myocardial perfusion imaging in aortic valve stenosis. Am F Cardiol 1977; 40: 889-99.

12 Finley JP, Howman-Giles R, Gilday DL, Rowe RD. Myocardial dysfunction in stressed newborns: thallium scans implicate ischemia (abstract). $A m \mathcal{F}$ Cardiol 1978; 41: 388.

13 Strauer BE, Bürger S, Büll U. Multifactorial determination of thallium-201 uptake of the heart: an experimental study concerning the influence of ventricular mass, perfusion and oxygen consumption. Basic Res Cardiol 1978; 73: 298-306.

14 Rabinovitch M, Fisher K, Gamble W, Reid L, Treves S. Thallium-201: quantitation of right ventricular hypertrophy in chronically hypoxic rats. Radiology 1979; 130: 223-6.

15 Rudolph AM, Cayler GC. Cardiac catheterization in infants and children. Pediat Clin North Am 1958; 5: $907-43$.

16 Nadas AS, Fyler DC. Pediatric cardiology. Philadelphia: W B Saunders, 1972: 668.

17 Rosenthal A, Tucker CR, Williams RG, Khaw KT, Strieder D, Shwachman H. Echocardiographic assessment of cor pulmonale in cystic fibrosis. Pediatr Clin North Am 1976; 23: 327-44.

18 Rimoldi HJA, Paiva REA, McAuley PC, Lev M. Mass indices of the ventricles at autopsy in children. Am Heart $\mathcal{f} 1971$; 81 : 770-80.

Requests for reprints to Dr Marlene Rabinovitch, Department of Cardiology, The Children's Hospital Medical Center, 300 Longwood Avenue, Boston, Massachusetts 02115, USA. 